\title{
1. Exploring Constructions of Space and Identity in Border Regions
}

Christian Wille and Rachel Reckinger

This volume explores spaces and identities in border regions. The programme thus pointedly phrased is based on a multi-layered research concept that combines methods of spatial and identity studies and integrates various thematic approaches. The point of departure is the notion that spaces and identities are brought about by social practices. Corresponding praxeological approaches that can also be expressed as doing space and doing identity focus on the performative or processual character, graphically conveyed with concepts such as 'doing geography', '(de)spatialization' or 'identity work' and 'identity politics'. This perspective, also adopted here, not only offers a wealth of starting points for the disciplines participating in this volume, it is moreover the one called for when dealing with investigations of and in border regions. For it is only constructivist and contingency-oriented approaches that provide adequate access to spatial and identity constructions in border regions which we argue conform only in a very limited way to 'nation-state orders' or to 'binary orders' of the here/there. Rather, in the case of border regions, one has to assume space- and identity-related 'logics of disorder' that manifest themselves in 'transversal' patterns of articulation, which themselves can be qualified as border regions or interstices, leading to practices that aim at the (re)institution of 'orders'. These and other processes of spatial and identity constructions are the subject matter of this volume and are reconstructed via institutional, media-based and everyday-cultural practices in border regions.

This thematic overview already suggests that in this volume the term of border region - and thus the border - will present itself in different forms and contexts. First of all in a political-administrative sense, it is Luxembourg and the adjoining regions in Germany, France and Belgium that provide the framework for the empirical research of the individual contributions in this volume. In addition, the term is used in a categorial sense when (mostly dichotomously defined) categories are applied or questioned. Finally, the term refers to 'spaces of the border' or (categorial) interstices that are produced by means of dynamic negotiations of differences. 
Constitutive for the term 'border region' or 'border area'1 are therefore borders or differences that are not understood as fixed and unquestioned positings, but rather as results of contingent practices. On the analytical level we differentiate between three intertwined 'practices of the border', through which spaces and identities not only materialize but which these also contribute in shaping: (1) the institution of borders as differentiations or regulations by the self or by other agencies with respect to the exterior; (2) the crossing of borders as an affirmative or subversive action with transformative potential and (3) the expansion of borders as an 'in-between' of manifold relations and overlaps (see section 2.1). Differentiating 'practices of the border' in this way helps to obtain an analytical perspective on the processes of negotiations of borders or of differences that are constitutive for constructions of space and identity. The case studies in this volume deal with practical relationalizations and topologies as well as with attributions of significations relating to the physical-material world which in turn inform about identity constructions. This is because distinctions, relations, 'speaking' of a here/there not only indicate (spatial) differentiations, but at the same time reveal information about (self)-positionings and thus identities.

This approach to spatial and identity constructions - on the basis of and along establishments, crossings and expansions of borders - is further differentiated conceptually in this volume, so that we can distinguish between two perspectives of investigation: with regard to spatial constructions we are dealing with institutional and media-based semanticizations and performative techniques of attribution and representation, as well as with everyday geographies as topological structures and symbolic spatializations on the subject level (see section 2.2). Similarly, identity constructions are investigated as identifications with and identifications of, focussing the attention on processes of attribution through specific institutions and, on the other hand, on everyday-cultural processes of appropriation of these attributions (see section 2.3). These two perspectives of investigation - one looking at the attributed and the other at the appropriated spaces and identities - are not considered separately but rather connected to reveal their empirical intersections and interlinkings in cross-border contexts. For this we draw primarily on Foucault's concept of governmentality - a concept sensitive to the constructedness of social reality, to issues of spatial and identity theory as well as to the interaction of different aspects and levels of the social (see section 2.3).

The three perspectives of investigation outlined above are dealt with in this volume in the framework of three research areas. They comprise (1) a powercritical perspective on spaces and identities that addresses particularly policies and

1 The synonymous use of the terms 'border region' and 'border area' in this volume is due to the different levels of investigation and is linked to the approach of the "social geography of everyday regionalizations" (Werlen 1997) (Personal translation of: "Sozialgeographie alltäglicher Regionalisierungen") (see section 2.2). 
normalizations that become effective and are negotiated in construction processes; (2) a media-oriented perspective on spaces and identities that sees media as constructors and projection surfaces and even as spaces (of negotiation) and (3) a subject-centered perspective that investigates the production of space and identity constructions in the course of everyday-cultural practices. The perspectives on spaces and identities adopted within the research areas complement each other and are developed both theoretically as well as empirically in chapters 3, 4 and 5 in a number of case studies.

\subsection{About this Publication}

The present publication was produced in the framework of a research project at the University of Luxembourg. The university-funded project with the title IDENT2 - Regionalizations as Identity Constructions in Border Areas ${ }^{2}$ (2011-2014) not only comprised a challenging and complex subject matter, but also relied on the participation of numerous scholars of the research unit IPSE (Identités, Politiques, Sociétés, Espaces), i.e. around 30 colleagues of its eight member institutes. ${ }^{3}$ The cross-disciplinary research context was conceived as a follow-up of the previous project IDENT - Socio-Cultural Identities and Identity Policies in Luxembourg $^{4}$ (2007-2010) (see IPSE 2010; IPSE 2011a; IPSE 2011b) that already centred on identity constructions. The present volume not only brings up to date the results attained there but also develops them substantially further. This is reflected in the expansion of the research question to include spatial construction and the particularities of cross-border investigation contexts; there is also a clear development on the conceptual and structural level, indicated by the complex research concept and the increased collaboration of the participating disciplines.

2 | Project management: Assoc. Prof. Dr. Sonja Kmec and Prof. Dr. Markus Hesse; project coordinators: Dr. Rachel Reckinger and Dr. Christian Wille.

3 | They comprise the Institute of Gender, Diversity and Migration, the Institute of Geography and Spatial Planning, the Institute of Philosophy, the Institute for History, the Institute of German Language, Literature and for Intercultural Studies, the Institute for Romance, Media and Art Studies, the Institute for Luxembourgish Language and Literatures, and the Institute of Political Science.

4 | Project management: Prof. Dr. Christian Schulz, project coordinators: Dr. Rachel Reckinger and Dr. Christian Wille. 


\begin{tabular}{|l|l|l|l|}
\hline & $\begin{array}{l}\text { Workgroup } \\
\text { Politics }\end{array}$ & $\begin{array}{l}\text { Workgroup } \\
\text { Media }\end{array}$ & $\begin{array}{l}\text { Workgroup } \\
\text { Subject } \\
\text { Constitutions }\end{array}$ \\
\hline Number of members & 6 & 12 & 13 \\
\hline $\begin{array}{l}\text { Number of } \\
\text { participating IPSE } \\
\text { institutes }\end{array}$ & 4 & 6 & 5 \\
\hline
\end{tabular}

Table 1: Composition of the content-related workgroups in the project IDENT2 Regionalizations as Identity Constructions in Border Areas

The work for this volume was carried out by the participating scholars in the framework of thematic and accompanying workgroups. The thematic workgroups each concerned themselves with one of the three research areas, tailoring them to the project's cross-disciplinary research concept in terms of theoretical and empirical principles. Despite the fact that the case studies are the product of individual research, the results of the collaboration are, as chapters 3, 4 and 5 show, the outcome of regular exchange and close coordination. The content-related project work was flanked by three accompanying workgroups that concentrated on theoretical issues, methodological aspects and the collaboration of the participating disciplines. As will become clear in chapter 2, the work accomplished here was critically important for the cross-disciplinary research concept and the collaboration of the participating scholars. The necessary exchange between content-related and accompanying workgroups was guaranteed via the colleagues and the project coordinators who were represented in both types of workgroups.

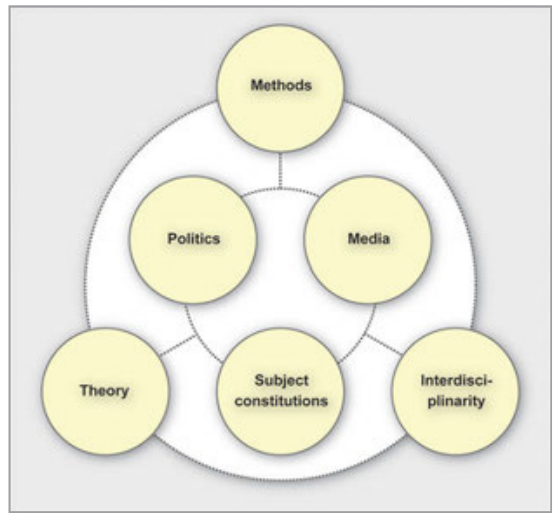

Figure 1: Content-related and accompanying workgroups in the project IDENT2 Regionalizations as Identity Constructions in Border Areas (design: Christian Wille, realization: Gilles Caspar and Malte Helfer) 
Finally we would like to thank all those without whom the IDENT2 project Regionalizations as Identity Constructions in Border Areas would not have been possible and who have been involved in supporting this enterprise and this publication. They include the 3,300 residents of Luxembourg and the adjoining regions who participated in the quantitative and qualitative surveys and all those who have actively supported and accompanied the project, in particular Gilles Caspar, Tilo Felgenhauer, Georg Glasze, Rouven Hehlert, Peggy Jacobs, Fem Alina Kaup, Bertrand Lévy, Guy di Méo, Birgit Neumann, Peter Schmitt-Egner, Verena Schreiber, Benno Werlen, Ruth Zimmerling, Sabine Zinn-Thomas and many more who remain unnamed. We express our gratitude to the University of Luxembourg for the generous financial support it lent to this cross-disciplinary research project. Last but not least we would like to thank the publisher transcriptVerlag for its professional cooperation as well as the translator and editor Matthias Müller who from a multilingual ${ }^{5}$ book manuscript marked by different disciplines and academic traditions has produced a German and an English version, the latter with the assistance of his colleague Jigme Balasidis.

\section{References}

IPSE (2010) (ed.): Doing Identity in Luxemburg. Subjektive Aneignungen - institutionelle Zuschreibungen - sozio-kulturelle Milieus, Bielefeld: transcript.

IPSE (2011a) (ed.): Doing Identity in Luxembourg. Subjective Appropriations - Institutional Attributions - Socio-Cultural Milieus, Bielefeld: transcript.

IPSE (2011b) (ed.): Construire des identités au Luxembourg. Appropriations subjectives - Projections institutionnelles - Milieux socio-culturels, Paris: Berg International.

Werlen, Benno (1997): Sozialgeographie alltäglicher Regionalisierungen. Band 2: Globalisierung, Region und Regionalisierung, Stuttgart: Franz Steiner Verlag.

5 | The participating researchers were free to write their contributions in either German, French or English. 
Christian Wille, Rachel Reckinger, Sonja Kmec, Markus Hesse (eds.)

\section{SPACES AND}

IDENTITIES IN

\section{BORDER REGIONS}

Politics - Media - Subjects

[transcript] Culture and Social Practice 
Christian Wille, Rachel Reckinger, Sonja Kmec, Markus Hesse (eds.) Spaces and Identities in Border Regions

Culture and Social Practice 
E-Book von Christian Wille, christian.wille@uni.lu

27.01.2016 17:18

Copyright 2016, transcript Verlag, Bielefeld 
Christian Wille, Rachel Reckinger, Sonja Kmec, Markus Hesse (eds.)

\section{Spaces and Identities in Border Regions}

Politics - Media - Subjects

\section{[transcript]}




\section{Bibliographic information published by the Deutsche Nationalbibliothek}

The Deutsche Nationalbibliothek lists this publication in the Deutsche Nationalbibliografie; detailed bibliographic data are available in the Internet at http://dnb.d-nb.de

\section{(๔) 2015 transcript Verlag, Bielefeld}

All rights reserved. No part of this book may be reprinted or reproduced or utilized in any form or by any electronic, mechanical, or other means, now known or hereafter invented, including photocopying and recording, or in any information storage or retrieval system, without permission in writing from the publisher.

Cover layout: Kordula Röckenhaus, Bielefeld

Cover illustration: misterQM / photocase.de

English translation: Matthias Müller, müller translations (in collaboration with Jigme Balasidis)

Typeset by Mark-Sebastian Schneider, Bielefeld

Printed in Germany

Print-ISBN 978-3-8376-2650-6

PDF-ISBN 978-3-8394-2650-0 